ENCUESTA DE CONOCIMIENTOS, CREENCIAS,

ACTITUDES Y PRÁCTICAS ACERCA DE LAS

ENFERMEDADES DE TRANSMISIÓN SEXUAL/VIH/SIDA

EN LOS ESTUDIANTES DEL INSTITUTO TECNOLÓGICO

DE SANTO DOMINGO (INTEC)

Julia Hasbún*

Miguel Suazo $^{\star \star}$

Martha Butler de Lister

\title{
CONCLUSIONES Y RECOMENDACIONES
}

En general, se puede concluir en base a los resultados de la muestra de los estudiantes de la INTEC, lo siguiente:

1) Acerca de los canales de información, los estudiantes universitarios se enteran más acerca del SIDA a través de los medios masivos más tradicionales como la televisión, periódicos, amigos, folletos y afiches. Consideran la universidad como el lugar más apropiado para informarles acerca de la sexualidad. Por lo tanto, las intervenciones educativas en las universidades son consideradas muy apropiadas por parte de la muestra. Los estudiantes de INTEC reportan preferir tener la información acerca de sexualidad de forma verbal y por videos. Como parte del pensum es un medio impopular que no debe usarse.

2) La mayoría de los estudiantes conoce lo que es una ETS y casi la totalidad sabe que el SIDA es mortal. Se observa desconocimiento en aspecto tales como que las ETS pueden producir es-

\footnotetext{
AIDSCAP

"Universidad INTEC
} 
terilidad, que las ETS en las mujeres son en más de la mitad asintomáticas. Que el flujo vaginal podría ser una ETS y que las relaciones sexuales con animales producen ETS. Esto se debe tener en cuenta para el diseño del contenido programático de las intervenciones educativas.

3) Se encontró un buen conocimiento de prevención de ETS, aunque se encuentran proporciones de un $40 \%$ a un $2 \%$ de estudiantes que reportan medidas erradas en protección de ETS. Si bien es cierto que el conocimiento de prevención es alto, este se puede mejorar.

4) El reconocimiento de cuáles son las enfermedades de transmisión sexual fue bueno. Mejor en el caso de SIDA, por lo que se sugiere, que sin restarle importancia al SIDA, se ofrezca información acerca de cuáles son las ETS y su prevención.

\section{Padecimiento de ETS.}

5) Sólo un $3 \%$ de los estudiantes de INTEC reconocen haber tenido una ETS. Y son las mujeres quienes más lo reconocen reportando haber tenido flujo vaginal. Esto no significa que en su mayoría puedan reconocer el flujo vaginal como una posible ETS. Se debe priorizar la información acerca de conocimientos para la identificación de ETS con signos y síntomas para ambos géneros.

6) El único hombre que reportó haber tenido una ETS (verrugas genitales) no buscó ayuda.

7) De las mujeres que reportan haber tenido una ETS y buscaron ayuda, una alta proporción reporta un buen manejo en general. Pero, en la consejería y orientación de condones y notificación de parejas, se observa bajos porcentajes de buen manejo.

8) En su mayoría las medidas preventivas para ETS, son reconocidas por los estudiantes de INTEC. Pero aún hay conocimientos errados como el que contesta más de las dos terceras partes de la muestra: conocer bien a las personas antes de tener relaciones sexuales. Y son los hombres quienes más lo reportan. Debe realizarse algún tipo de actividad educativa que refuerce las medidas correctas de prevención de ETS que ya los estudiantes 
saben, y que eliminen esas creencias erradas que confunden a la población.

\section{Percepción de Riesgo de Contagio de ETS.}

9) El riesgo percibido de contagio de ETS es bajo. Si se toma en cuenta que un $69 \%$ de las mujeres de lá muestra no eran sexualmente activas, se puede entender esto ya que no tienen relaciones sexuales. Estas perciben en mayor medida que los hombres, ninguna posibilidad de contagio.

\section{Conocimiento y Prevención de SIDA.}

10) Las medidas de prevención de SIDA son muy bien reconocidas. Sin embargo aún se reportan a excepción de algunas medidas de higiene en general (como evitando baños públicos) y prevención de otras epidemias que no previenen el SIDA. Es tiempo de que se trabaje con la erradicación de estas creencias asociadas al SIDA. Estas pueden llevar a conductas prejuiciosas como no tocar a una persona con SIDA o estar cerca de ellas, conductas que aíslan a la persona con SIDA y la condenan a una distancia social y humana negativa. También, creencias como que el mosquito puede transmitir el virus de VIH son peligrosas, ya que debe quedar claro que la persona puede realmente evitar el contagio de $\mathrm{VIH}$, sin tener el temor de que por casualidad lo picó un mosquito infectado. Casi una quinta parte de la muestra de estudiantes universitarios de INTEC lo creen.

11) El conocimiento de una persona con SIDA o que haya muerto de SIDA es alto. Lo que no sabemos qué tan cercano fue el conocimiento de esa persona. (Se recomienda una investigación cualitativa para determinar esto). Son las mujeres quienes más conocen a personas con VIH o SIDA.

12) Menos de la mitad y en su mayoria hombres son los que reportan haber cambiado su conducta sexual por el SIDA. Un 55\% de los estudiantes de ambos sexos no es sexualmente activo. Esto deja un $10 \%$ de personas que contestan que no han cambiado su conducta. De los que sí han cambiado su conducta sexual, casi la 
mitad dice haber comenzado a usar condones y un poco menos redujo número de parejas sexuales. Casi un $40 \%$ le pidió a su pareja (compuesto en su mayoría por mujeres).

\section{Condones.}

13) Es alto el conocimiento de dónde obtener condones. Pero son las mujeres las que responden más no poder obtener condones y reconocer menos lugares o personas de expendio. El mercadeo del condón debe dirigirse a ambos sexos

14) En los últimos 12 meses, aproximadamente un tercio de la muestra de estudiantes dice haber usado siempre el condón. Una proporción parecida dice nunca haberlo utilizado.

En cuanto a la última relación sexual, un poco más de la mitad utilizó el condón. De los que no usaron el condón, más de dos tercios tuvieron la relación coital con pareja fija y menos de un tercio de los estudiantes con pareja ocasional.

Es importante concientizar a ambos sexos de la importancia del condón tanto con pareja fija como con pareja ocasional.

\section{Sexualidad}

15) Un cuarto de la muestra ha tenido más de una pareja sexual en los últimos tres meses. Esta proporción debe disminuir con intervenciones dirigidas a la reducción de parejas como área prioritaria. Sobre todo en los hombres. El cambio de parejas aparece también cercano a un cuarto de la muestra de estudiantes. En los últimos tres meses (período que es corto) un $27 \%$ reporta pareja nueva.

16) Más de la mitad de la muestra sexualmente activa, tuvo penetración vaginal con condón. Pero un $45 \%$ no lo usó. No importando si es con pareja fija u ocasional, se debe insistir en el uso de condones. 